\title{
When Socio-Culture Meets Socio-Economy
}

\section{Jin Kuan Kok*}

Department of Psychology and Counseling, Universiti Tunku Abdul Rahman, Malaysia

\begin{abstract}
Clarification of the term "Young-Old" as proposed by Neugarden is made. Two main factors that contributed to the differences in the findings of the article entitled "Aging Gracefully: A Comparative Study of Japanese and Malaysia Women Aged 65-75 are discussed. This article concluded that socio-religious pressure would probably, in time, give way to socio-economic pressure. The challenges faced by care givers when socio-religious factors have to give way under the pressure of economic forces will be further discussed. As the traditional Malaysian Chinese culture might not change in the near future because many young people are still holding to traditional values of filial piety, greater strain will be imposed on the younger Malaysian Chinese generations. This paper concludes that ageing is not only a personal experience and it has to be understood in its macro socio-economic context.
\end{abstract}

\section{When Socio-Culture Meets Socio-Economy}

The response to being invited to write a review of one's own published article entitled "Aging Gracefully: A Comparative Study of Japanese and Malaysia Women Aged 65-75 is a mixed one [1]. Any pleasure is naturally clouded by anxiety about having sufficient critical rigour and detachment to review one's own work. In this paper I will start with what changes I would like to make, and continue to discuss the two issues highlighted in the article, namely socio-religious and socio-economic differences, with a particular focus on the values of filial piety, that account for the differences found in the two groups of women of the two countries: Japan being at the continuum of developed while Malaysia is still a developing country. Japan is the world's leading 'grey' population with more than a quarter of its citizens aged 65 or above by 2025 while Malaysia is a 'young' country, with only $5.5 \%$ of its population aged 60 in 2013 and this percentage is likely to double only between 2010 to $2040[2,3]$

\section{Who Defined or Decided What is Meant by "Young- Old"}

The 'snapshot' of the ageing experience described in my earlier articles showed that the lived experience of the women from the two countries was a continuity of their life experience which was a product of their society $[1,4]$. The terms "Young-Old" or "Old-Old" were coined and were not meant to be exclusively bound to actual age divisions as that would be, rightly, be criticized as oversimplification [5]. Neugarten specifically described the young-old as the group composed of those aged between 55 and 75 . What is experienced as being "Young-Old" has to be within a context. The comparison of studies of both Japanese and Malaysian women showed that some Malaysian women who were 65 looked older than Japanese women who were 70. One reason was that 65 year old Malaysian women, who had had employment, would have enjoyed 5 years of retirement, while a 70 year old Japanese woman, who is biologically 5 years older, would have been retired for 10 years. The former might have been trapped by family household chores and looking after grandchildren while the latter is more likely to have enjoyed personal development by pursuing self-interests or aesthetic activities. Therefore if the definition of "Young-Old" refers to a post retirement stage in which women can further develop before disabilities set in, then for Malaysian women the "Young-Old" would be between 60-70, taking into consideration that Japanese women live on average 9 years longer than Malaysian women [1].

Furthermore, the educational levels between these two groups of women were shown, in my earlier studies, to have been very different. It was extremely difficult to find a Japanese research participant who had received only primary school education $[1,4]$. However, the educational level for Malaysian women aged 65-75 was generally much lower. Education provides the knowledge necessary for development therefore it plays an important role in the ageing experience. Prior life experience will determine the ageing experience so distinct stages of life are blurred as past experience influences future decisions and development.

Therefore I would suggest that future studies about "the young-old" need to consider the prior life experiences of the research participants. In the video "Nothing as Rich as Human Life" declared: "A person who is 65 is a product of what he's been before" [6]. Thus, "Young-old" is a term that needs to be contextualized and it is not appropriate apply it rigidly.

\section{Macro Environment}

In my previous article, I tentatively concluded that socio-religious pressures would probably give way to socio-economic ones as time goes on. This statement is probably overly simplistic as it only gave precedence to the economic development and the sophistication of the formidable cultural aspects was not elaborated. Therefore in this paper I will highlight the sophistication of the matter of what happens when socio-religious factors, especially the values of filial piety, meet socioeconomic pressures. Although this may sounds like a local perspective related to two oriental groups of women, these two main concepts can be applied globally. Economic growth is always the leading force, but cultural values are always persistent and formidable.

Ageing is never merely an individual or a personal experience. Neugarten could not agree more with this as her life's work endeavored to bridge the two elements of human development: psychology and sociology; one being micro and the other macro. The complication of

*Corresponding author: Jin Kuan Kok, Department of Psychology and Counseling, Faculty of Arts and Social Science Universiti Tunku Abdul Rahman, Jalan Universiti, Bandar Baru Barat, 31900 Kampar, Perak, Malaysia, Tel: 6054652806,E-mail: kokjk@utar.edu.my

Received November 23, 2015; Accepted December 08, 2015; Published December 14, 2015

Citation: Kok JK (2015) When Socio-Culture Meets Socio-Economy. Health Care Current Reviews 3: 149. doi: 10.4172/2375-4273.1000149

Copyright: (c) 2015 Kok JK. This is an open-access article distributed under the terms of the Creative Commons Attribution License, which permits unrestricted use, distribution, and reproduction in any medium, provided the original author and source are credited. 
"when socio-culture meets socio-economy" is that both are formidable forces, one being internalized and another exerted by the macro environment.

After completing my paper, I had the opportunity to visit Japan in October, 2014. It was my first visit to Tokyo, Japan as I did not interview the Japanese research participants myself: that was done by another researcher. The trip to Japan was remarkably inspiring. The infrastructure of public transport was well developed and convenient and enabled elderly people to travel everywhere by themselves. Besides taking a pleasant walk through the beautiful greenery of the Palace and river sides, like Meiji and his Empress, I had the opportunities to take a long walk from Yanaka (谷中) to Ueno Park and finally to the National Museum. While I was strolling through a huge graveyard at Yanaka, I met many young-old and old-old, strolling along the graveyard paths. There were many information boards about famous people along the graveyard paths. There were many cozy, unconventional shops, selling art and crafts along the streets. Later I learnt that this cultural scenario is very common in Japan. National museums, public libraries, Zoos and Parks were within walking distance or easily accessible by public transport. I felt for the first time that growing old is not necessarily depressing. Even though one has to cope with change and loss, it is not too difficult to be alone when surrounded by such a fabulous and rich textures of cultural tradition.

By contrast, Malaysian young-old women are still working to survive. Their socio-economic situation means that they do not have access to the sort of culture and recreation enjoyed by Japanese women. After launching their adult children into independence, many Japanese women are able to pursue their own interests while most Malaysian women still relied on family members for their financial security and future care [1]. Most Malaysian Chinese are second generation immigrants. They still live in family-centered cultural constructs and aspire only to help care for their young grandchildren so that their children can go out to work. Socio-economic factors prevent Malaysian Chinese "young-old" from developing their untapped potential or aesthetic interests. Given the bleak scenario of the government care system in Malaysia, most elderly in Malaysians expect to be cared for by informal care givers and mostly by family members. The values of filial piety prevail. It is not common for the old to be sent to retirement homes or nursing homes as it is considered to be abandonment.

Moreover, neither government provision of formal care, nor the private care industry, is as flourishing as in some other Asian countries such as Taiwan or Singapore. Policy makers might be taking the availability of family careers for granted to evade the challenges of taking care of the elderly.

In Malaysia, filial piety used to be the Asian cultural norm, and not only among Malaysian Chinese as other ethnic groups also share this value. It is similar to an imperative religious belief which demands obedience with some even worshiping their deceased parents. As family size is getting smaller the burden on care-givers will become increasingly heavy. Being in the same global village, with the influence of increased education levels and the awareness of the needs of autonomy and independence for the next generation, it is expected that there will be a transition of cultural or religious norms. However, cultural values can be quite persistent and formidable. Modern Japanese culture has discarded the value of filial piety which was described as "having done injustice to Japanese women" as women were always the caregivers. This traditional value still prevails among Malaysian Chinese families [7] investigated Malaysian Chinese values and found that most families sent their children to Chinese Independent Schools so that their children would learn and follow their traditional values. With this practice, one can foresee that the concept of filial piety might not fade away so easily. Japanese society has such common values as fighting spirit and aesthetic pursuits to unite its people therefore "young-old" women are able to flourish in aesthetic pursuits. While Malaysian Chinese young-olds, being second generation immigrants from China might not accept other cultural values from the society in which they are embedded, and they are not surrounded by the monuments of their own cultural past so will stick to the core Chinese value of filial piety.

Predictable problems are as follows: The current young-olds of Malaysian participants (who are quite similar to the baby boomers in the U.S. who were born between 1946 - 1958 and who have gone through wars or hardship in life) and subsequent generations will probably experience a transition of cultural or religious norms. There will be widespread awareness that filial piety will become burdensome, they themselves have to work hard in the paid labor force to earn enough to take care of their parents, yet at the same time have to save up enough for their own retirement because they too, have started to feel the need to be independent, "Not to cause trouble to others" in Japanese women's terms. How could this young-old group or future young-old Malaysian women have the time to enjoy or further develop their interests let alone aesthetic pursuits, after raising their children, when they have to support an independent life and to take care of their finances for the future? Some Japanese women may need to care for their family members when young-old, but there are a great variety of leisure opportunities and aesthetic activities to choose from. These choices and opportunities are not so available to Malaysian Chinese women.

Malaysian women may be expected to adopt similar characteristics of Japanese women as time goes on because to be independent seems to be a norm. Both socio-cultural and economic factors exert influence on their expectations of care and on the need for independence. It is expected the care burden will increase among the Malaysia Chinese young-old.

Can Malaysian Chinese women expect to pursue their interests and be involved in aesthetic activities like Japanese women do, to bring grace and humanity to the last stage of their lives? And when will that become possible? My conclusion from my above critical examination of the complexity of the meeting of these two: Socio-culture and socio-economy is: There is no simple answer to this question. There is no such issue of which will give way to another as there is always adaptation between the two and it largely depends on the macro environmental supports. The welfare of the aged is always related to the welfare that is available in their society, which basically means the provision and support of their families. However, the persistent force that deeply rooted in the culture cannot be underestimated as shown in the comparative studies of the two groups of Japanese and Malaysian women. It is critical that policy makers will not take for granted the cultural value of filial piety to help individuals to flourish during their young-old life stage.

\section{References}

1. Kok JK, Yap YN (2014) Aging gracefully: A comparative study of Japanese and Malaysian women aged 65-75. Journal of Aging Studies 31: 54-61.

2. Hurd MD, Yashiro N (1996) The economic effects of aging in the United States and Japan. University of Chicago Press.

3. Department of Statistics, Malaysia (2013) Retrieved from

4. Kok JK, Yap YN (2015) A Comparative study between Malaysian Chinese 
women and Japanese women aged 65-75 on their experience and view on ageing. International Journal of Social Science and humanity, 5: 1045-1049.

5. Neugarten BL (1974 ) Age Groups in American Society and the Rise of the Young-Old. The ANNALSof the American Academy of Political and Social Science. September 415:187-198.
6. Neugarten (1995) "Nothing as Rich as Human Life". Interviewed by W. Andrew Achenbaum. Chicago, Illinois: Buehler Center on Aging, Northwestern University.

7. Siah Poh Chua, Christina Ong Sook Beng, Tan Swee Mee, Sim Chzia Poaw (2015) Perception on Chinese values: A comparison of Chinese secondary students studying at national secondary schools and Chinese independent schools in Malaysia 52: 62-68. 